
Functions for a Particle Swarm Optimization Tuned PID Controller with Derivative Filter

\author{
Erdinç ŞAHIN ${ }^{1 *}$, Mustafa Şinasi AYAS ${ }^{2}$ \\ ${ }^{1}$ Karadeniz Teknik Üniversitesi, Of Teknoloji Fakültesi, Enerji Sistemleri Mühendisliği Bölümü, Trabzon. \\ ${ }^{2}$ Karadeniz Teknik Üniversitesi, Mühendislik Fakültesi, Elektrik-Elektronik Mühendisliği Bölümü, Trabzon. \\ *Sorumlu yazar e-posta: esahin@ktu.edu.tr ORCID ID: https://orcid.org/0000-0002-9740-599X \\ msayas@ktu.edu.tr ORCID ID: https://orcid.org/0000-0001-8113-4817
}

Geliş Tarihi: 01.02.2019; Kabul Tarihi: 15.10.2019

\author{
Keywords \\ Error-based objective \\ functions; User- \\ defined objective \\ functions; Classical PID \\ controller; PSO \\ algorithm; Transient \\ and steady state \\ response analysis.
}

\begin{abstract}
In this study, we investigate the performance analysis of transient and steady state characteristics of the commonly used error-based objective functions (EBOF) such as integral of squared error (ISE), integral of time weighted squared error (ITSE), integral of absolute error (IAE), and integral of time weighted absolute error (ITAE) and a user-defined objective function (UDOF). In optimization process, particle swarm optimization (PSO) algorithm tuned proportional-integral-derivative controller with derivative filter (PIDF) is employed for a second order plus dead time (SOPDT) test system. Simulation results shows the superiority of the UDOF in terms of settling time, overshoot, and settling minimum value compared to EBOFs.
\end{abstract}

\title{
Parçacık Sürü Optimizasyonu Ayarlı Türev Etkisi Filtreli Bir PID Denetleyici için Hata Tabanlı ve Kullanıcı Tanımlı Amaç Fonksiyonlarının Performans Analizi
}

\begin{abstract}
Anahtar kelimeler Hata tabanlı amaç fonksiyonları; Kullanıcı tanımlı amaç fonksiyonları; Klasik PID denetleyici; PSO algoritması; Kalıcı ve geçici durum analizi.

Öz

Bu çalışmada, hatanın karesinin integrali (HKi), zaman ağırlıklı hatanın karesinin integrali (ZAHKi), mutlak hatanın integrali (MHi) ve zaman ağırlıklı mutlak hatanın integrali (ZAMHi) gibi control sistemleri tasarımında sık kullanılan hata tabanlı amaç fonksiyonları (HTAF) ile kullanıcı tanımlı amaç fonksiyonlarının (KTAF) geçici ve kalıcı durum tepkilerinin performans analizi incelenmiştir. Optimizasyon sürecinde, parçacık sürüsü optimizasyonu (PSO) algoritması tarafından ayarlanan türev etkisi filtreli oransal-integral-türevsel denetleyici, ikinci dereceden ölü zamanlı bir test sistemi için kullanılmıştır. Simülasyon sonuçları, KTAF'ıN oturma zamanı, aşım ve alt aşım değerlerindeki üstünlüğünü göstermektedir.
\end{abstract}

(C) Afyon Kocatepe Üniversitesi

\section{Introduction}

One of the main stages in controller design process is optimization of the controller parameters, which may cause undesired or unstable system responses. Without optimized parameters, a controller cannot show its actual performance on system dynamic.
Commonly used controller type in industry is definitely proportional-integral-derivative (PID) controller. It has been used more than 100 years due to its advantageous of simplicity, applicability and functionality (Ang et al. 2005). Whereas, PID controller has a poor performance on systems consist of uncertainty, complex dynamics and 
nonlinearity. PID controller has also 3 independent parameters: proportional action constant $K_{P}$, integral action constant $K_{I}$ and derivative action constant $K_{D}$. These parameters should be optimally tuned to obtain a satisfactory system response.

Analytical methods such as pole placement, state space design and frequency analysis have been already introduced for PID controller design process for many years. Due to computational drawbacks, these kind of numerical methods have forced researches to study on metaheuristic optimization algorithms (Lee and Geem 2005).

Most of the metaheuristic algorithms are nature inspired and they are developed by considering some features of nature (Yang 2010). Modern metaheuristic algorithms are almost guaranteed to find optimal solutions for a wide range of optimization problems encountered in different engineering applications (Yang 2010).

One of these popular metaheuristic algorithms is PSO algorithm. In 1995, American social psychologist James Kennedy, and engineer Russell C. Eberhart developed PSO method. PSO, a population-based algorithm, is a computational search algorithm used to optimize a constrained problem iteratively (Kennedy and Eberhart 1995). It is inspired by swarm intelligence of flocks of birds and shoals of fish (particles) and its concept consists of mimicking the particles behaviors by using velocity and position equations (Eberhart and Shi 2001).

Due to easy design and robust convergence rate, PSO algorithm has gained attention and found in many applications such as antenna design, biomedical, communication networks, clustering and classification, control systems, electronics and electromagnetics, engines and motors, metallurgy, robotics, scheduling, power systems and plants, signal processing and sensor networks, etc. (Poli 2008). Also, PSO, as a most commonly used optimization method, has varied types of modifications: chaotic PSO, fuzzy based PSO, bare-bones PSO, hybridization with genetic algorithm (GA), Tabu search (TS), artificial bee colony $(A B C)$, ant colony optimization ( $A C O)$, etc., extensions of multi-objective, discrete, constrained, etc. All of these above-mentioned studies are implemented to increase convergence speed and rate of PSO algorithm to the optimal solution (Zhang et al. 2015).

There are many types of objective functions employed by PSO algorithm for tuning of PID controller parameters. Some of these are user defined aggregation functions consisting of rise time, maximum overshoot, settling time, errorbased performance functions, steady state error, phase margin, gain margin and magnitude of control signal, etc. (Itik et al. 2015, Gaing 2004, Zamani et al. 2009, Latha et al. 2013). Commonly, error-based objective functions such as integral of absolute error (IAE), integral of squared error (ISE), integral of time-weighted absolute error (ITAE) and integral of time-weighted squarederror (ITSE) are often used in controller design process since they can be easily evaluated analytically (Stimac et al. 2014, Deepyaman et al. 2008, Giriraj Kumar et al. 2010, Sharaf and Gammal 2009, Nagaraj and Murugananth 2010). However, these performance criterions may be insufficient in terms of transient and steady state response characteristics of the system to be controlled (Gaing 2004).

There are lots of studies based on PSO tuned PID controller in the literature by aiming to minimize different kind of objective functions. However, we cannot see a study that analyze the transient and steady states performances of commonly used error-based and user-defined objective functions, yet. Therefore, in this study, we investigated the transient and steady state characteristic performances of commonly used objective functions IAE, ISE, ITAE, ITSE, and a user defined one. For transient performance analysis, maximum percentage overshoot $\left(M_{p}\right)$, rise time $\left(t_{r}\right)$, settling time $\left(t_{s}\right)$ and settling minimum value (SMV) are considered and steady-state error $\left(E_{s s}\right)$ is calculated for steady-state performance analysis. In optimization process, PSO algorithm is 
employed by considering proposed objective functions. The optimization problem is to optimize 3 independent parameters of a PIDF controller. A SOPDT transfer function is used as a benchmark system.

The rest of this paper is organized as follows. PIDF controller structure, PSO algorithm basics and optimization process titles are discussed in Section 2. Results and Discussion are described in Section 3. Finally, Conclusion is stated in Section 6.

\section{Materials and Methods}

\subsection{PID Controller with derivative filter (PIDF)}

Approximately $90 \%$ of the control systems use the PID controller and its different combinations $(\mathrm{P}, \mathrm{I}, \mathrm{PI}, \mathrm{PD})$ because of its simple structure and good stability (Aström and Hagglund 2001, Wang Barnes and Cluett 1995). A conventional PID controller has 3 actions which are proportional, integral, and derivative. Proportional action with proportional constant $\left(\mathrm{K}_{\mathrm{P}}\right)$ provides an overall control action proportional to size of error signal. Integral term with its gain $\left(K_{1}\right)$ is used to eliminate steady offset from a constant reference signal. Finally, derivative term with gain $\left(K_{D}\right)$ improves the transient response of the system to be controlled (Johnson and Moradi 2006). Parallel form mathematical representation of a conventional PID controller is given below.

$G_{P I D}(s)=\frac{U(s)}{E(s)}=K_{P}+\frac{K_{I}}{s}+K_{D} s$

where $U(s)$ and $E(s)$ are control and error signals in frequency domain. Practically, it is not recommended to use derivative action (D) of PID controller alone because of derivative kick effect and undesirable noise amplification. In order to eliminate these undesirable behavior of derivative action, it is usually used with a firstorder low-pass filter. The derivative filtered form transfer function of a classical PID controller can be written as Eq. 2.
$G_{P I D}(s)=\frac{U(s)}{E(s)}=K_{P}+\frac{K_{I}}{s}+K_{D} s \frac{N}{s+N}$

In simulations, parallel form PIDF controller with a derivative filter coefficient $(\mathrm{N}=100)$ is used. Block diagram presentation of a parallel form PID controller with filtered D-action is shown in Figure 1.

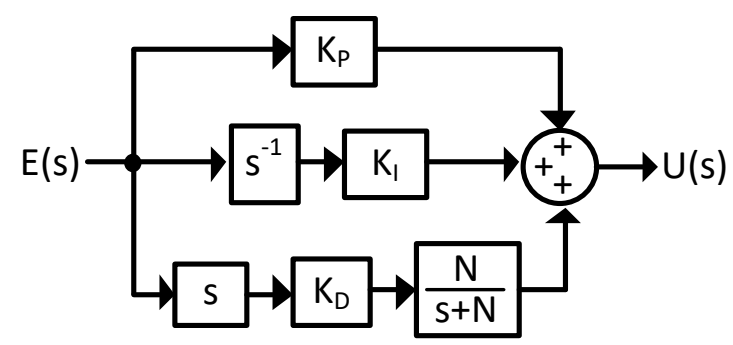

Figure 1. Parallel form PIDF controller block diagram with filtered $D$-action.

\subsection{Basics of PSO algorithm}

As depicted in introduction part, PSO simulates a social system of particles in nature. In PSO algorithm, every particle in the population has a memory to keep its local best solution $\left(P_{\text {best }}\right)$ with an objective function value which is generally based on mathematical equations. The compared overall best solutions of these $P_{\text {best }}$ values is called as $G_{\text {best }}$ which is called as global best solution (Eberhart and Shi 2001). At each iteration, particles velocity $(v)$ and positions $(x)$ are updated according to equations given below for the next step.

$V_{i d}^{k+1}=W_{*} V_{i d}^{k}+c_{1^{*}} r_{1^{*}}\left(p_{i d}^{k}-X_{i d}^{k}\right)+$

$c_{2^{*}} r_{2^{*}}\left(g_{\text {id }}^{k}-X_{i d}^{k}\right)$

$X_{i d}^{k+1}=X_{i d}^{k}+V_{i d}^{k+1}$

where $k$ is the iteration number, $i$ is the particle number, $d$ is the dimension of the search space which is $3\left(K_{P}, K_{1}, K_{D}\right)$ for this study, $c_{1}$ and $c_{2}$ are the acceleration factors of the velocity function and these parameters are selected as 2. $r_{1}$ and $r_{2}$ are uniformly random numbers. $w$ is the inertia weight which balances the global and local search 
and it is changed linearly from $w_{\max }(=0.9)$ to $w_{\text {min }}(=0.4)$ as recommended in (Gaing 2004). The equation given below is used to calculate inertia weight by considering maximum and current iteration numbers.

$$
W=W_{\max }-\frac{W_{\max }-W_{\min }}{i t r n} \text { itrn }_{\text {max }} \text { current }
$$

where maximum iteration number and current iteration number is symbolized as itrn $n_{\max }$ and $i_{\text {itrn }}$ current, $_{\text {,espectively. }}$

The flowchart of a PSO algorithm adapted to the controller parameters tuning process of a PID controller are depicted in Figure 2.

\subsection{Optimization process}

In optimization process, PSO algorithm is employed for 10 times for each investigated objective functions. Each run consists of 50population size and 50-maximum iteration number. That means, Matlab/Simulink model file is run 25000 times for each objective functions. A schematic presentation of the optimization process is shown in Figure 3.

In Figure 3, we see a negative feedback closed loop control system where $(e)$ is the error signal that is the difference between the reference signal (Ref.) and measured system output ( $y$ ), and $(u)$ is the control signal which is directly used as an input for the benchmark SOPDT transfer function.

The mathematical definitions of the investigated objective functions used in simulations for this study are given as follows.

$$
\begin{aligned}
& I A E=\underset{0}{t_{\text {end }}}|e(t)| d t
\end{aligned}
$$

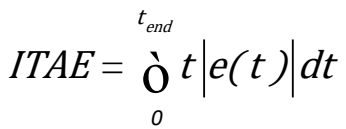

$$
\begin{aligned}
& I S E=\underset{0}{\mathrm{o}} e(t)^{2} d t
\end{aligned}
$$

$$
\begin{aligned}
& I T S E=\underset{0}{t_{\text {end }}} \operatorname{te}(t)^{2} d t \\
& U D O F=W_{1} I S E+w_{2} M_{p}+w_{3} t_{s}
\end{aligned}
$$

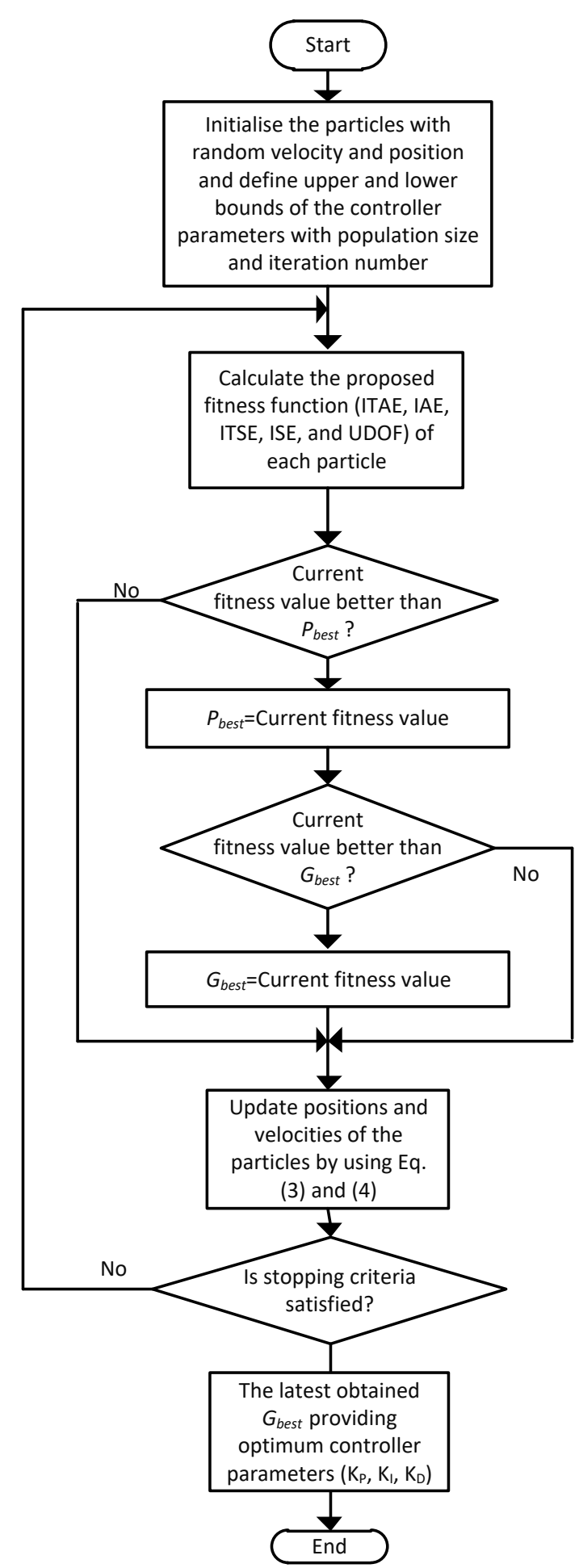

Figure 2. Flowchart of the PSO algorithm. 


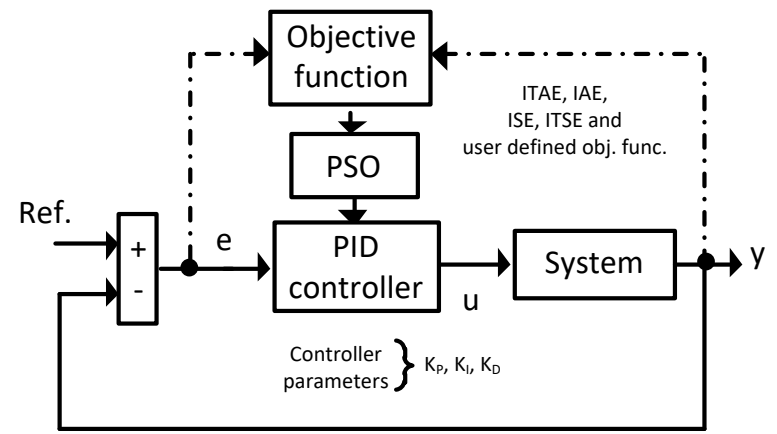

Figure 3. Schematic representation of the PIDF controller optimization process.

In Eq. (10), UDOF means user defined objective function for optimization process of PID controller parameters. This function has been already used in (Latha et al. 2013). Proposed UDOF consists of ISE performance index and transient system response parameters: $M_{p}$ and $t_{s}$ with different weighting coefficients. The weighting parameters $w_{1}, w_{2}$, and $w_{3}$ for UDOF are assigned as 1,1 , and 0.5 as recommended in (Latha et al. 2013). In addition, $t$ symbolizes time, $t_{\text {end }}$ is the simulation time which is set to 20 seconds. Sampling time $\left(T_{s}\right)$ is selected as $10 \mathrm{~ms}$. The upper and lower limiting bounds of all PID parameters $\left(K_{P}, K_{l}\right.$, and $\left.K_{D}\right)$ are searched in the range of $[0,10]$ in the search space.

\section{Results and Discussion}

As emphasized in (Karasakal et al. 2005), most of the high-order processes system can be modeled by using a first order plus dead time (FOPDT) or a second order plus dead time (SOPDT) transfer functions. So, we use a SOPDT transfer function as a test system. To analyze effects of the parameters of the PSO algorithm in PID controller design, simulation of a SOPDT model is performed in Matlab/Simulink platform. The transfer function of the SOPDT model used in the study is given below.

$$
G_{B S}(s)=\frac{1}{(s+1)^{2}} e^{-s}
$$

The change of objective functions for each running time of PSO algorithm are shown in Figure 4. As seen from the figure, PSO algorithm has a consistent convergence rate for EBOFs and It is succeeding to converge approximately the same objective function value for EBOFs. Whereas, convergence rate and speed to the optimal solution for UDOF are changing iteratively because of consisting of 3 independent performance measure indexes which are ISE, $M_{p}$, and $\mathrm{t}_{\mathrm{s}}$.

The results (optimal PID parameters and objective function values) of these convergences are given in Table I. In simulations, the controller parameters proving minimum objective function value are considered (marked as bold in Table I). Also, in Figure 5, the best convergence results of OFs are given together.

Unit step system responses of optimized controllers are depicted in Figure 6. The controller parameters satisfying the optimal solution for PID controller are given in Table II with the step response transient and steady states characteristics: settling time $\left(t_{s}\right.$, threshold $2 \%$ ), rising time ( $t_{r}$, from $10 \%$ to $90 \%$ ), maximum percentage overshoot ( $\left.\mathrm{M}_{\mathrm{p}} \%\right)$, steady-state error $\left(E_{s s}\right)$ and settling minimum value (SMV). Comparison results show that UDOF provides the best $M_{p}, t_{s}, S M V$, and $E_{s s}$ values without oscillation in the system response. However, it ensures the highest $t_{r}$ value which causes a slow system response up to reach reference signal. Among the error-based objective functions, ITAE provides the lowest $M_{p}$ and $t_{s}$ values. Also, SMV and $E_{s s}$ values of the ITAE function are better than the other EBOFs. That means lower oscillation in system response is obtained with ITAE function. However, $t_{r}$ value of ITAE is the longest time which means a slow system response just as UDOF based PIDF. ISE function provides the most oscillated system response with the worst $M_{p}$, SMV and $t_{s}$ characteristics. Whereas, it has the best $t_{r}$ parameter value. 

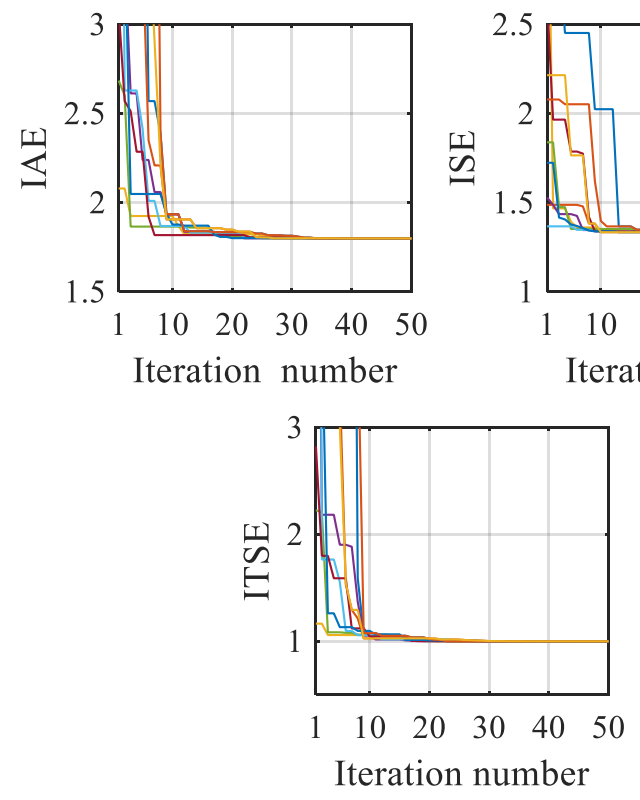
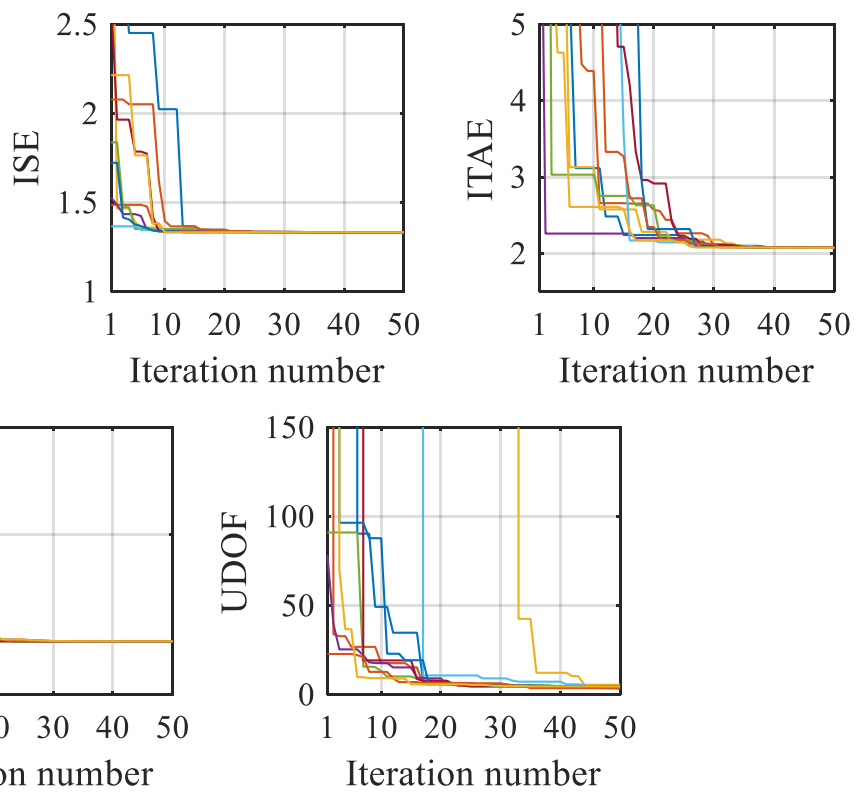

Figure 4. Changes of OFs values for 10 running.

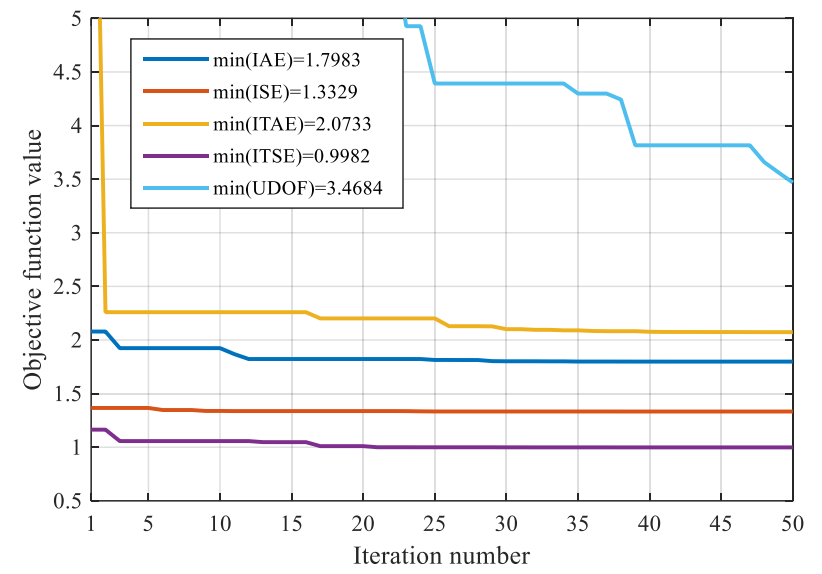

Figure 5. Changes of OFs for the best trial.

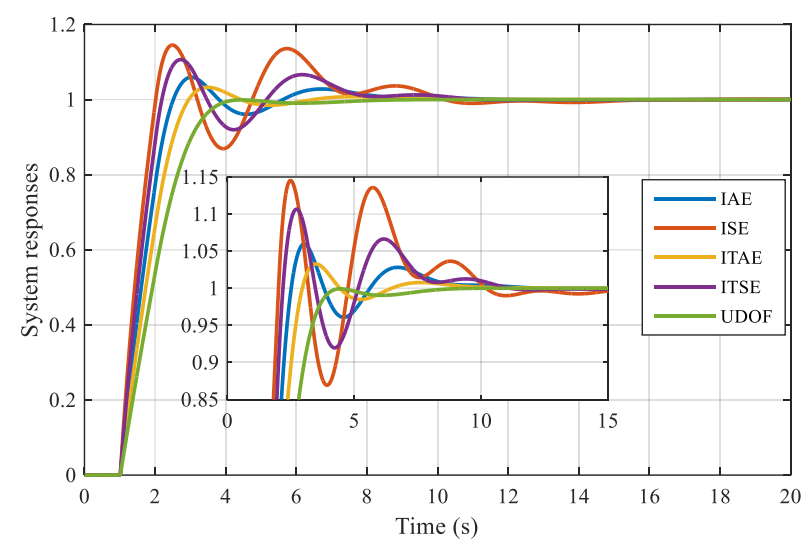

Figure 6. System responses with PIDF controllers based on IAE, ITAE, ISE, ITSE, and UDOF.
In addition, amplitude change of control efforts of the controllers are graphically compared in Figure 7. UDOF provides the minimum control effort which may be considered for some sensitive applications. Among the error-based objective functions, ITAE function ensures the minimum control effort.

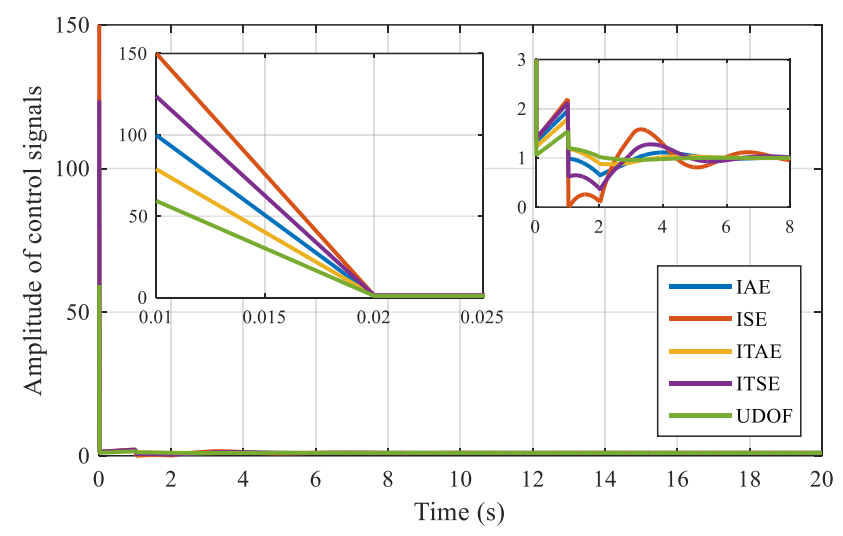

Figure 7. Amplitude of control signals of PID controllers based on IAE, ITAE, ISE, ITSE, and UDOF.

\section{Conclusion}

In this study, we aimed to compare transient and steady states performances of commonly used EBOFs (IAE, ITAE, ISE and ITSE) and a UDOF for metaheuristic optimized controller design problems. For this purpose, we use one of the most 
popular metaheuristic algorithm, PSO, and a wellknown controller type, PIDF. As a benchmark system, we have a SOPDT transfer function. UDOF can easily meets the designer criteria based on system response characteristics. On the other hand, ITAE function seems to be best choice for controller design process compared to other EBOFs.

For future work, studied objective functions may be compared in detail with other user defined aggregation functions introduced in literature by using recently introduced metaheuristic algorithms. Also, the performances may be compared on different type of transfer functions by applying not only step reference signal but also sinusoidal, ramp, and impulse input signals

\section{References}

Ang, K. H., Chong, G. and Li, Y., 2005. PID control system analysis, design, and technology. IEEE Transactions on Control Systems Technology, 13,559-576.

Åström, K. J. and Hägglund, T., 2001. The future of PID control. Control Engineering Practice, 9, 1163-1175.

Deepyaman, M., Ayan, A., Mithun C., Amit K. and Ramdoss, J., 2008. Tuning PID and $\mathrm{PI}^{\lambda} \mathrm{D}^{\mu}$ controllers using the integral time absolute error criteria. International Conference on Information and Automation for Sustainability (ICIAFS), 457-462.

Eberhart, R.C. and Shi, Y., 2001. Particle swarm optimization: developments, applications and resources. IEEE Proceedings of the Evolutionary Computation Congress, 1, 81-86.

Gaing, Z. L., 2004. A particle swarm optimization approach for optimum design of PID controller in AVR system. IEEE Transactions on Energy Conversion, 19, 384-91.

Giriraj Kumar, S. M., Jayaraj D. and Kishan A. R., 2010. PSO based tuning of a PID controller for a high performance drilling machine. International Journal of Computer Applications, 1, 12-18.

Itik, M., Sahin, E. and Ayas M. S., 2015. Fractional order control of conducting polymer artificial muscles. Expert System with Applications, 42, 8212-20.
Johnson M. A. and Moradi M. H., 2006. PID control: new identification and design methods, Springer Science \& Business Media, 7-9.

Karasakal, O., Yeşil E., Güzelkaya M. and Eksin I., 2005. Implementation of a new self-tuning fuzzy PID controller on PLC. Turkish Journal of Electrical Engineering \& Computer Sciences, 13, 277-286.

Kennedy J. and Eberhart R., 1995. Particle swarm optimization. IEEE International Conference on Neural Networks, 1942-1948.

Latha K., Rajinikanth V. and Surekha P. M., 2013. PSObased PID controller design for a class of stable and unstable systems. ISRN Artificial Intelligence, 2013, 1-11.

Lee K. S. and Geem Z. W., 2005. A new meta-heuristic algorithm for continuous engineering optimization: harmony search theory and practice. Computer methods in applied mechanics and engineering, 23, 3902-33.

Nagaraj B. and Murugananth N., 2010. A comparative study of PID controller tuning using GA, EP, PSO and ACO. IEEE International Conference in Communication Control and Computing Technologies (ICCCCT), 305-313.

Poli R., 2008. Analysis of the publications on the applications of particle swarm optimization. Journal of Artificial Evolution and Applications, 2008, 1-10.

Sharaf A. M. and El-Gammal A. A., 2009. An integral squared error-ISE optimal parameters tuning of modified PID controller for industrial PMDC motor based on Particle Swarm Optimization-PSO. IEEE International Conference in Power Electronics and Motion Control (IPEMC), 1953-1959.

Štimac, G. Braut S.and Žigulić R., 2014. Comparative analysis of PSO algorithms for PID controller tuning. Chinese Journal of Mechanical Engineering, 27, 92836.

Wang Barnes L. T. J. D. and Cluett W. R., 1995. New frequency-domain design method for PID controllers. IEE Proceedings-Control Theory and Applications, 142, 265-271. 
Yang X. S., 2010. Engineering Optimization: An Introduction with Metaheuristic Applications, John Wiley \& Sons, XXVI.

Zamani, M., Karimi-Ghartemani M., Sadati N. and Parniani M., 2009. Design of a fractional order PID controller for an AVR using particle swarm optimization. Control Engineering Practice, 17, 13807.

Zhang Y., Wang S. and Ji G., 2015. A comprehensive survey on particle swarm optimization algorithm and its applications", Mathematical Problems in Engineering, 2015, 1-38.

Table 1. Optimization results of the investigated OFs. (Bold signifies the best result)

\begin{tabular}{|c|c|c|c|c|c|c|c|c|}
\hline \multirow{2}{*}{ \# runs } & \multicolumn{4}{|c|}{ IAE } & \multicolumn{4}{|c|}{ ITAE } \\
\hline & $K_{p}$ & $K_{\mathbf{I}}$ & $K_{D}$ & IAE & $K_{p}$ & $K_{\mathbf{l}}$ & $K_{D}$ & ITAE \\
\hline 1.run & 1.3239 & 0.6385 & 0.9882 & 1.7983 & 1.2327 & 0.5745 & 0.7898 & 2.0743 \\
\hline 2.run & 1.3246 & 0.6375 & 0.9865 & 1.7983 & 1.2231 & 0.5708 & 0.7788 & 2.0733 \\
\hline 3.run & 1.3257 & 0.6366 & 0.9854 & 1.7983 & 1.2323 & 0.5751 & 0.7873 & 2.0740 \\
\hline 4.run & 1.3262 & 0.6390 & 0.9869 & 1.7983 & 1.2242 & 0.5711 & 0.7772 & 2.0733 \\
\hline 5.run & 1.3259 & 0.6383 & 0.9875 & 1.7983 & 1.2214 & 0.5704 & 0.7741 & 2.0733 \\
\hline 6.run & 1.3250 & 0.6359 & 0.9859 & 1.7983 & 1.2266 & 0.5721 & 0.7810 & 2.0734 \\
\hline 7.run & 1.3247 & 0.63833 & 0.9866 & 1.7983 & 1.2247 & 0.5683 & 0.7781 & 2.0742 \\
\hline 8.run & 1.3256 & 0.6382 & 0.9881 & 1.7983 & 1.2250 & 0.5717 & 0.7791 & 2.0733 \\
\hline 9.run & 1.3239 & 0.6385 & 0.9882 & 1.7983 & 1.2247 & 0.5727 & 0.7808 & 2.0735 \\
\hline 10.run & 1.3246 & 0.6375 & 0.9865 & 1.7983 & 1.2267 & 0.5714 & 0.7755 & 2.0738 \\
\hline \multirow{2}{*}{ \# runs } & \multicolumn{4}{|c|}{ ISE } & \multicolumn{4}{|c|}{ ITSE } \\
\hline & $\mathrm{K}_{\mathrm{p}}$ & $K_{I}$ & $K_{D}$ & ISE & $K_{p}$ & $K_{I}$ & $K_{D}$ & ITSE \\
\hline 1.run & 1.3753 & 0.8199 & 1.4882 & 1.3329 & 1.4023 & 0.7174 & 1.2233 & 0.9982 \\
\hline 2.run & 1.3757 & 0.8201 & 1.4884 & 1.3329 & 1.4023 & 0.7186 & 1.2243 & 0.9982 \\
\hline 3.run & 1.3759 & 0.8195 & 1.4871 & 1.3329 & 1.4025 & 0.7177 & 1.2232 & 0.9982 \\
\hline 4.run & 1.3772 & 0.8206 & 1.4869 & 1.3329 & 1.4011 & 0.7170 & 1.2214 & 0.9982 \\
\hline 5.run & 1.3759 & 0.8201 & 1.4874 & 1.3329 & 1.4024 & 0.7181 & 1.2227 & 0.9982 \\
\hline 6.run & 1.3768 & 0.8193 & 1.4880 & 1.3329 & 1.4024 & 0.7181 & 1.2226 & 0.9982 \\
\hline 7.run & 1.3764 & 0.8197 & 1.4872 & 1.3329 & 1.4030 & 0.7182 & 1.2217 & 0.9982 \\
\hline 8.run & 1.3767 & 0.8194 & 1.4878 & 1.3329 & 1.4031 & 0.7171 & 1.2199 & 0.9982 \\
\hline 9.run & 1.3753 & 0.8199 & 1.4882 & 1.3329 & 1.4023 & 0.7174 & 1.2233 & 0.9982 \\
\hline 10.run & 1.3757 & 0.8201 & 1.4884 & 1.3329 & 1.4023 & 0.7186 & 1.2243 & 0.9982 \\
\hline \multirow{2}{*}{ \# runs } & \multicolumn{4}{|c|}{ UDOF } & & & & \\
\hline & $K_{p}$ & $K_{1}$ & $K_{D}$ & UDOF & & & & \\
\hline 1.run & 1.2939 & 0.5191 & 0.9450 & 4.5713 & & & & \\
\hline 2.run & 1.0530 & 0.4882 & 0.5840 & 3.4683 & & & & \\
\hline 3.run & 0.9820 & 0.4243 & 0.8427 & 5.5497 & & & & \\
\hline 4.run & 1.1482 & 0.5319 & 0.7343 & 3.7298 & & & & \\
\hline 5.run & 1.2862 & 0.4968 & 1.0661 & 4.5486 & & & & \\
\hline 6.run & 0.9834 & 0.4535 & 0.4892 & 3.7298 & & & & \\
\hline 7.run & 1.2936 & 0.5075 & 1.0242 & 4.5364 & & & & \\
\hline 8.run & 1.3267 & 0.5078 & 1.0828 & 4.4745 & & & & \\
\hline 9.run & 1.0454 & 0.4796 & 0.5676 & 3.5140 & & & & \\
\hline 10.run & 1.2875 & 0.5035 & 1.0395 & 4.5394 & & & & \\
\hline
\end{tabular}

Table 2. System response characteristics with optimized PID controller parameters. (Bold signifies the best result)

\begin{tabular}{ccccccccc}
\hline \multirow{2}{*}{$\begin{array}{c}\text { Objective } \\
\text { function }\end{array}$} & \multicolumn{4}{c}{ PID Controller parameters } & \multicolumn{5}{c}{ System response characteristics } \\
\cline { 2 - 9 } & $\mathbf{K}_{\mathbf{p}}$ & $\mathbf{K}_{\mathbf{I}}$ & $\mathbf{K}_{\mathbf{D}}$ & $\mathbf{M}_{\mathbf{p}} \%$ & $\mathbf{t}_{\mathbf{r}}$ & $\mathbf{t}_{\mathbf{s}}$ & $\mathbf{S M V}$ & $\mathbf{E}_{\mathbf{s s}}$ \\
\hline IAE & 1.3257 & 0.6366 & 0.9854 & 5.963 & 1.11 & 7.48 & 0.960 & $8.006 \mathrm{e}^{-5}$ \\
ITAE & 1.2242 & 0.5711 & 0.7772 & 3.272 & 1.37 & 3.95 & 0.984 & $1.161 \mathrm{e}^{-5}$ \\
ISE & 1.3768 & 0.8193 & 1.4880 & 14.51 & $\mathbf{0 . 8 0}$ & 9.57 & 0.869 & $2.714 \mathrm{e}^{-4}$ \\
ITSE & 1.4025 & 0.7177 & 1.2232 & 10.65 & 0.92 & 7.46 & 0.919 & $1.191 \mathrm{e}^{-4}$ \\
UDOF & 1.0530 & 0.4882 & 0.5840 & $\mathbf{0 . 0 0 2}$ & 1.85 & $\mathbf{3 . 6 7}$ & $\mathbf{0 . 9 9 0}$ & $\mathbf{1 . 0 8 9}^{-6}$ \\
\hline
\end{tabular}

